of greater quality.

But Kitcher should not be blamed if he has found difficulties in developing a positive account of the value of life and how it relates to decisions about which lives to create and sustain. These are problems that no-one has fully resolved. Kitcher's arguments are always compassionate, always ingenious and always worth pursuing. The book is refreshingly direct and honest, well illustrated with real examples presented in sufficient detail for a full understanding of the dilemmas they raise, and is a more than welcome addition to what will undoubtedly be a growing literature on these important topics.

John Harris is at the Centre for Social Ethics and Policy, University of Manchester, Oxford Road, Manchester M13 9PL, UK.

\section{Uncertain futures}

\section{Crispin Tickell}

One World: The Health and Survival of the Human Species in the 21st Century. Edited by Robert Lanza. Health Press, Santa Fe, New Mexico: 1996. Pp. 325. $\$ 25$.

ROBERT Lanza has put together an ambitious compendium of short essays about the human condition in the next century. With millennial thoughts in many people's minds, it is a good time to do so. Other societies and civilizations, indeed other animal species, have greatly affected the natural environment around them. But we are perhaps the first human generation to be able to see and assess the global consequences of our actions on the land, waters and atmosphere of our planet.

Since the Industrial Revolution got under way some 250 years ago, and humans began to multiply at their present giddy-making rate (over 90 million more people every year), change has accelerated, sometimes steadily, at other times in bewildering spurts. In the past, generations could communicate with each other over the years on the basis of a slowly evolving but common vocabulary, common experience and common outlook. That is no longer so. With sharp discontinuities behind and before us, uncertainties have greatly increased and prediction has become more hazardous than ever.

It cannot be said that most of the contributors to this book say much that is new or interesting. They constitute an impressive array of the great and the good and sometimes powerful, from the secretary general of the United Nations and the heads of certain of its agencies to prominent scientists, doctors and a selection of ministers of health. A much used

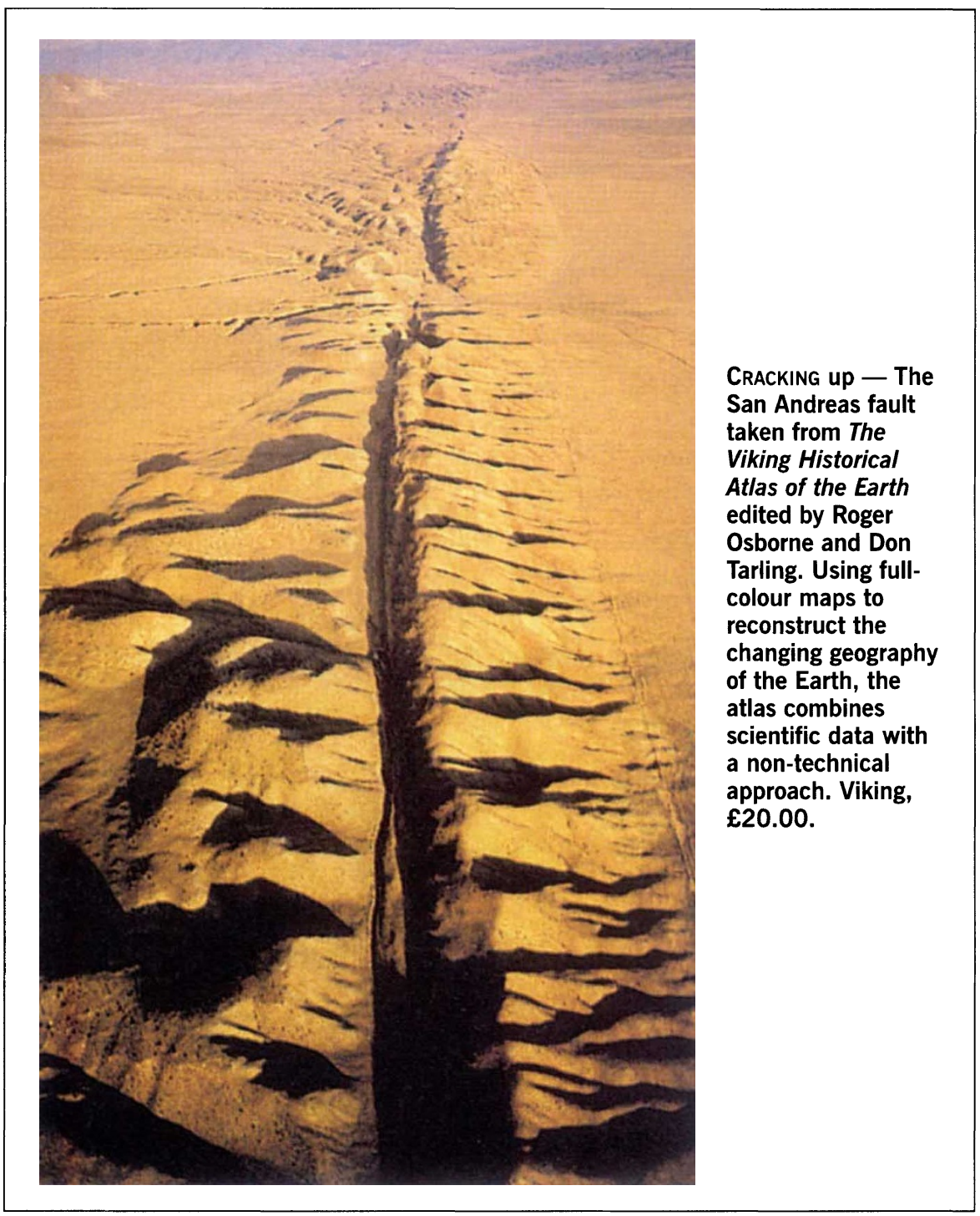

word throughout the book is 'challenge'. It seems usually to mean inability to cope, or in some cases to understand what is happening. It begs the question of whether the authors are so great and good after all.

The contributors fall into four main categories. There are those from the ruling establishment who state the worthy, the obvious and the well meaning. The hand of the speech-writer and publicrelations man is visible from time to time. If some of these eminent persons had really thought through and written their essays themselves, the result would not have been like this (or let us hope not). There are those preoccupied with the short term, in particular those involved in medicine, who struggle with the worldwide problem of rising health costs and changing patterns of disease. Many in this group tend to see the future as an extrapolation of the present. Next there are a few with endearing bees in their bonnets who at least stand out for being different and in one case for some colourful waffle. Here also are one or two with outsized egos. Finally there are those with some- thing genuinely original to say. Among them are Linus Pauling, Christian Barnard and Carl Sagan as dissenters from the prevailing wisdom, Robert Gallo, Jonathan Mann and Luc Montagnier on AIDS; and W. Harding Le Riche for an analysis that constitutes a cry of pain at what we are doing to the world, and what may come of it.

Essays of this kind are far harder to write than a full-length book. The task set was almost too difficult. Even so, few manage to get their minds around the issues as a whole, or see each issue in terms of the others. Prediction may be impossible, but a greater sense of interconnectedness, of wider ranging across the disciplines, would have shed more light on the prospects ahead. One thing is sure. The future will not be as anyone expects: less upwards and onwards, more sideways in unfamiliar directions, and even sometimes downwards or backwards. Ten years into the next century, this book will be a period piece.

Crispin Tickell is at Green College, Woodstock Road, Oxford OX2 6HG, UK. 